EXTENDED REPORT

\title{
Self reported non-vertebral fractures in rheumatoid arthritis and population based controls: incidence and relationship with bone mineral density and clinical variables
}

\author{
R E Ørstavik, G Haugeberg, T Uhlig, P Mowinckel, J A Falch, J I Halse, T K Kvien
}

Ann Rheum Dis 2004;63:177-182. doi: 10.1136/ard.2003.005850

See end of article for authors' affiliations

Correspondence to:

Dr R Ørstavik, Department of Rheumatology,

Diakonhjemmet Hospital

Box 23, Vinderen, N-0319

Oslo, Norway;

ragnhild.orstavik@

ioks.uio.no

Accepted 28 April 2003

\begin{abstract}
Objective: To compare the incidence of self reported non-vertebral fractures after RA diagnosis between female patients with RA and control subjects, and to explore possible associations between non-vertebral fractures and bone mineral density (BMD), disease, and demographic factors.

Methods: 249 women (mean age 63.0 years) recruited from a county register of patients with RA and population controls $(n=249)$ randomly selected after matching for age, sex, and residential area were studied. Data on previous non-vertebral fractures were obtained from a detailed questionnaire, and BMD was measured at the hip and spine.

Results: 53 (21.3\%) patients with RA had had 67 fractures after RA diagnosis, the corresponding numbers for controls were $50(20.1 \%$ ) and 60 (odds ratio (OR) for paired variables for overall fracture history 1.09, $95 \% \mathrm{Cl} 0.67$ to 1.77$)$. The overall fracture rates per 100 patient-years were 1.62 and 1.45 , respectively, but self reported hip fractures were increased in RA ( $10 \vee 2, O R 9.0,95 \% \mathrm{Cl} 1.2$ to 394.5). Patients with a positive fracture history had longer disease duration, were more likely to have at least one deformed joint, and had lower age and weight adjusted BMD than those with no fracture history. In logistic regression analysis, fracture history was independently related to BMD only.

Conclusions: With the probable exception of hip fractures, non-vertebral fractures do not seem to be a substantial burden in RA. Similar independent relationships between levels of BMD and fracture history were found in patients with RA and in population based controls.
\end{abstract}

$\mathrm{P}$ tients with rheumatoid arthritis (RA) have an increased risk of osteoporosis and osteopenia. ${ }^{1}$ Furthermore, a substantial proportion of patients with RA receive corticosteroid treatment, which has been shown to increase the risk of both vertebral and non-vertebral fractures. ${ }^{2-6}$ However, rather few studies have explored the rates of fractures in patients with RA. It has been demonstrated that patients with RA have a higher risk of vertebral deformities $^{58}$ and hip fractures ${ }^{9}$ than control subjects. Two previous studies have suggested that aging, impaired ambulation and, perhaps, corticosteroid use are independently associated with non-vertebral fractures in RA. ${ }^{11}{ }^{12}$ Only one of these studies compared the incidence of non-vertebral fractures in patients with RA with that in control subjects, finding an overall increased risk of about $50 \% .{ }^{11}$ This study was performed as far back as in 1984, without the currently applied methods of defining RA, disease activity, or severity. No previous studies on non-vertebral fractures in RA included bone mineral density (BMD) measurements.

This study aimed at comparing the incidence of self reported non-vertebral fractures in a representative cohort of female patients with RA aged 50-72 years with the incidence in individually matched control subjects. Secondly, we wanted to examine possible relationships between a positive fracture history and BMD, corticosteroid use, markers of disease activity, and other possible risk factors for non-vertebral fractures.

\section{MATERIALS AND METHODS \\ Patients and controls}

The Oslo RA register consists of patients fulfilling the American College of Rheumatology 1987 revised classification criteria for RA, ${ }^{13}$ and who have a residential address in the county of Oslo. The completeness of the register is $85 \%$, and details of the register have been extensively described previously. ${ }^{14}{ }^{15}$ The inclusion criteria of this study were enrolment in the Oslo RA register, female sex, Caucasian race, disease duration of at least 2 years, and year of birth between 1926 and 1948 (age at least 50 at study onset).

Patients were recruited from a representative subgroup of the RA register who had been part of an epidemiological study including BMD measurements 2 years previously. ${ }^{1} \mathrm{~A}$ single control for each patient was randomly selected from the population register of Oslo, after matching for age, sex, and residential area. Possible controls were asked by letter, and a reminder was sent if no answer was received within a month. If one declined, a second subject was identified.

\section{Evaluation of non-vertebral fractures}

While attending the clinical examination, all patients received a detailed questionnaire, including questions on non-vertebral fractures obtained after the age of 25. Participants were specifically asked for fractures at the wrist, humerus, ankle, tibia, and hip, and the year in which the fracture occurred. They were then asked to mark whether the fracture was due to a traffic accident, skiing accident, occurred during other sports activities, was work related, or if they fell while walking or standing. A separate column was left for additional remarks. In the statistical analyses, fractures were stratified as to whether they had occurred before or after the time of RA diagnosis (by at least one year). All fractures due to traffic accidents were excluded.

Abbreviations: $B M D$, bone mineral density; DAS, Disease Activity Score; RA, rheumatoid arthritis; RF, rheumatoid factor 
For verification of this recording, we performed a "blinded" telephone interview with 129 subjects (87 patients with RA and 42 controls), of whom 60 (47\%) had reported any previous fracture. The interviews were performed about 2-3 years after the first investigation. The patients were asked the same questions as in the original questionnaire and, in addition, more detailed questions about diagnosis and treatment.

\section{BMD analysis}

BMD measurements of the hip (total hip and femoral neck) and the lumbar spine (L2-4, anterior-posterior) were performed using the same dual energy $x$ ray absorptiometry equipment (Lunar Expert, Madison, Wisconsin). T and Z score estimations were computed from a pooled European/ American reference database. Detailed descriptions of the reference database, equations for computing age and weight adjusted Z score estimations, and quality control procedures have been published previously. ${ }^{16}$

\section{Collection of clinical and demographic variables}

All measurements were performed during 1998-2001. Demographic, patient and disease characteristics, including conventional RA disease core measurements (table 1), were recorded partly by self reported questionnaires and partly by interview and clinical examination. A specially trained research nurse (patients with RA) or medical student (control group) performed the latter in cooperation with a rheumatologist (REØ or GH). Joint assessment included 28 swollen joint count; 28 tender joint count; and 18 deformed joint count (patients with RA). The Disease Activity Score (DAS) was computed using the 28 joint counts. ${ }^{17}$ Patients with a rheumatoid factor ( $R F)$ titre $\geqslant 64$ measured on at least one occasion were classified as RF positive.

\section{Statistical analyses}

Differences between patients and controls were analysed by applying paired $t$ tests (continuous data) or by McNemar's test for counts. Odds ratios and $95 \%$ confidence intervals for paired variables were computed if allowed by the distribution of data sets. Patients with and without a history of any peripheral fracture were compared for their demographic and clinical variables and BMD, using $t$ tests (continuous variables) and $\chi^{2}$ tests (counts). Kaplan-Meier survival analysis was applied to compare time to event between patient and controls. A dummy year of disease onset was set

Table 1 Demographic and disease characteristics for patients and controls (mean (SD) for continuous variables, $\%$ for counts)

\begin{tabular}{|c|c|c|c|c|}
\hline Clinical and demographic variables & No & Patients & Controls & p Value \\
\hline Age (years) & 249 & $63.0(6.8)$ & $63.4(6.7)$ & $<0.001$ \\
\hline Height $(\mathrm{cm})$ & 249 & $164.2(6.0)$ & $163.7(5.9)$ & 0.36 \\
\hline Weight (kg) & 249 & $66.1(12.5)$ & 69.5 (11.9) & 0.002 \\
\hline BMI $\left(\mathrm{kg} / \mathrm{m}^{2}\right)$ & 249 & $24.5(4.4)$ & $25.9(4.2)$ & $<0.001$ \\
\hline Disease duration (years) & 249 & $16.6(10.4)$ & & \\
\hline RF positive (\%) & 239 & 51.9 & & \\
\hline DAS28 & 230 & 4.7 (1.2) & & \\
\hline MHAQ & 248 & $1.7(0.6)$ & $1.1(0.2)$ & $<0.001$ \\
\hline 18 Deformed joints count & 249 & $4.5(1.1)$ & & \\
\hline Smoking status & 239 & & & \\
\hline Current smoker (\%) & & 33.1 & 30.1 & 0.56 \\
\hline Previous smoker (\%) & & 66.1 & 58.2 & 0.08 \\
\hline Current DMARD use (\%) & & 55.4 & & \\
\hline Corticosteroid use & 249 & & & \\
\hline Current users (\%) & & 47.8 & 2.4 & $<0.001$ \\
\hline Ever users (\%) & & 69.5 & 11.1 & $<0.001$ \\
\hline Long term users* $(\%)$ & & 53.0 & 2.4 & $<0.001$ \\
\hline \multicolumn{5}{|l|}{ Bone protecting agents } \\
\hline Oestrogens & 249 & & & \\
\hline Current users (\%) & & 43.4 & 29.3 & 0.002 \\
\hline Ever users (\%) & & 57.8 & 48.0 & 0.04 \\
\hline Bisphosphonates & 249 & & & \\
\hline Current users (\%) & & 12.0 & 1.2 & $<0.001$ \\
\hline Ever users (\%) & & 16.0 & 1.6 & $<0.001$ \\
\hline Calcitonin & 249 & & & \\
\hline Current users (\%) & & 0.8 & 0.8 & 1.00 \\
\hline Ever users (\%) & & 4.3 & 1.3 & 0.09 \\
\hline Calcium supplement & 249 & & & \\
\hline Current users (\%) & & 61.8 & 20.9 & $<0.001$ \\
\hline Ever users (\%) & & 73.1 & 26.9 & $<0.001$ \\
\hline Vitamin D supplement & 249 & & & \\
\hline Current users (\%) & & 72.5 & 57.3 & $<0.001$ \\
\hline Ever users (\%) & & 80.4 & 66.3 & $<0.001$ \\
\hline \multicolumn{5}{|l|}{$B M D$ variables } \\
\hline BMD femoral neck $\left(\mathrm{g} / \mathrm{cm}^{2}\right)$ & 226 & 0.80 & 0.87 & $<0.001$ \\
\hline BMD total hip $\left(\mathrm{g} / \mathrm{cm}^{2}\right)$ & 226 & 0.83 & 0.91 & $<0.001$ \\
\hline BMD L2-4 $\left(\mathrm{g} / \mathrm{cm}^{2}\right)$ & 245 & 1.06 & 1.11 & 0.005 \\
\hline Z score femoral neck & 226 & -0.26 & 0.24 & $<0.001$ \\
\hline Z score total hip & 226 & -0.42 & 0.16 & $<0.001$ \\
\hline Z score of the spine & 245 & 0.25 & 0.58 & 0.02 \\
\hline
\end{tabular}

No, complete pairs, numbers differ because of missing data.

When variables appear in both pairs, significance of difference is tested with paired $t$ test for continuous variables and McNemar's tests for dichotomous variables.

BMI, body mass index; MHAQ, modified Health Assessment Questionnaire; DAS, Disease Activity Score; DMARD, disease modifying antirheumatic drug

*Ever users for 12 months or more. 
for the matched controls, corresponding to the time of disease onset of the paired patient. Possible independent predictors of non-vertebral fractures were subsequently entered into a logistic regression analysis, applying a positive history of any non-vertebral peripheral fracture as dependent variable. Factors were included in the first model if there was a significance level below $\mathrm{p}=0.20$ in the bivariate analysis, and then removed one by one until all variables had a statistically significant contribution in the final model. Patients and controls were also pooled together in logistic regression analysis to test whether a diagnosis of RA was independently related to a previous non-vertebral fracture.

All tests were two sided, and the level of significance was set to $\mathrm{p}=0.05$.

\section{RESULTS}

\section{Demographic and disease characteristics of patients} and controls

Table 1 shows the demographic and disease characteristics of the 249 patients and 249 controls. Group differences of importance were found for body weight, body mass index, disability level, use of corticosteroids, and osteoporosis drug treatment. Patients with RA had significantly lower BMD and $\mathrm{Z}$ scores at all measurement sites than controls. Hypertension was recorded in $16.5 \%$ of the patients with RA compared with $24.2 \%$ of the controls $(\mathrm{p}=0.04)$; occurrence of other concomitant diseases was similar. Fifty five $(22.1 \%)$ controls self reported a rheumatic disease other than RA, most commonly chronic musculoskeletal pain syndromes or osteoarthritis.

\section{Representivity of the patient cohort}

The total number of patients with RA fulfilling the entry criteria was 528, and the final participant rate in this study was $249(47.2 \%)$. The non-attending patients $(\mathrm{n}=279$, $52.8 \%$ ) comprised 154 patients not meeting for the initial clinical examination, 75 patients not attending the initial BMD examination, and 41 patients not attending the follow up. In nine cases we were not able to identify suitable controls. The patients finally included in the analyses were slightly younger than the RA register patients who fulfilled the entry criteria and did not participate (mean difference (CI) 1.67 (0.51 to 2.79) years). There were no statistically significant differences in disease duration or presence of RF. Among patients who met for clinical examination two years previously $(\mathrm{n}=358)$, no statistically significant differences were found between those included in the present study $(n=249)$ and those who declined to attend $(n=109)$ for measurement of the following clinical variables: disability score from the modified Health Assessment Questionnaire, DAS, prednisolone use, or ever use of disease modifying antirheumatic drugs. Thus, it is considered that the patients included are fairly representative of the entire underlying patient population in the county of Oslo born between 1926 and 1948.

In addition to the included controls, letters were sent to 168 who either declined $(n=69)$ or who did not respond $(\mathrm{n}=99)$. Thus, the final attendance rate was $59.8 \%$.

\section{History of non-vertebral fractures}

One or more non-vertebral fractures after the age of 25 were reported by 71 patients $(28.5 \%)$. Fifty three $(21.3 \%)$ patients had had a total of 67 non-vertebral fractures after onset of RA (fig 1), corresponding with a rate of 1.62 fractures per 100 patient-years. In the control group, 71 subjects (28.5\%) reported having had one or more non-vertebral fractures after the age of 25 , and $50(20.1 \%)$ had had a total of 60 fractures after the dummy time of disease onset (corresponding to the

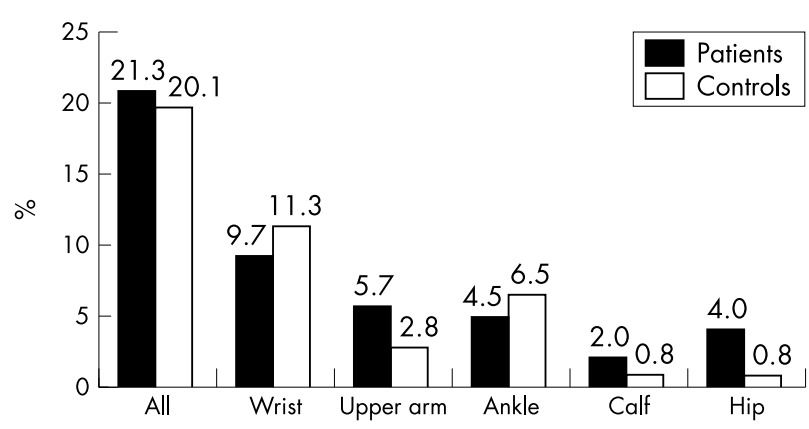

Figure 1 Non-vertebral fractures (\%) after RA diagnosis in 249 female patients and 249 matched controls.

onset of RA in the paired patient) (rate 1.45 non-vertebral fractures per 100 person-years). Figure 1 shows that the difference between patients with RA and controls for overall fracture history was not significant (odds ratio (OR) for paired variables $1.09,95 \%$ CI 0.67 to 1.77 ). The difference for hip fractures was statistically significant (10 patients $v 2$ controls, OR 9.0, 95\% CI 1.2 to 394.5). Twice as many humerus fractures occurred in the RA groups than in controls, and more wrist and ankle fractures in the control group, but these differences did not reach statistical significance.

Survival analysis with time from RA diagnosis to first nonvertebral fracture showed an equal distribution between time and event in patients and controls (fig 2, log rank test $\mathrm{p}=0.73)$.

In the RA group, $3 / 67$ (4.5\%) non-vertebral fractures (all radius) reported after diagnosis occurred during skiing or other sports activities, compared with $13 / 60$ (21.7\%) in controls (seven radius, four ankle, one humerus and one leg) (difference $17.2 \%, 95 \%$ CI $5.6 \%$ to $29.5 \%$ ). If these fractures were excluded from analysis, the odds ratio for any fracture in the RA group was 1.56 (95\% CI 0.91 to 2.68).

\section{Verification of non-vertebral fractures}

One hundred and twenty one (94\%) of the 129 participants gave the same answer(s) in the telephone interview as they self reported in the questionnaire. Eight participants (6\%) gave a different answer. One of these (a patient with RA) had previously reported a wrist fracture, which was not reported in the telephone interview. The remaining seven subjects all reported a positive fracture history on both occasions, but the number or type of fracture(s) was different. In all cases, the diagnosis and treatment reported seemed likely for the current type of fracture. However, there was a larger difference in time span: in 17/59 (29\%) cases with a positive fracture history, the year of fracture did not

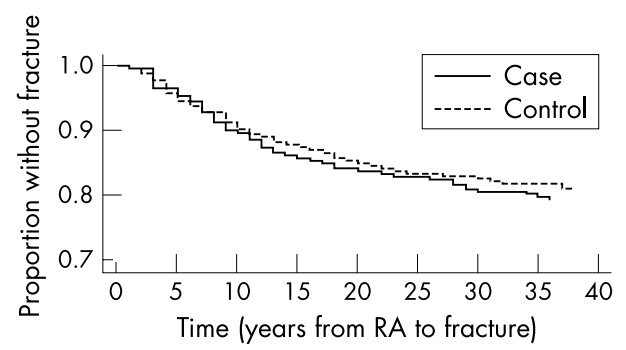

Figure 2 Proportion without fracture in 249 patients with RA and 249 matched controls. $0=$ time of RA onset. A dummy time was set for controls, corresponding with the year of disease onset for the matched patient with RA. Kaplan-Meier survival plot. 
Table 2 Comparisons of patients and controls with and without a previous non-vertebral fracture (mean (SD) for continuous variables, \% for counts)

\begin{tabular}{|c|c|c|c|c|c|c|}
\hline & \multicolumn{3}{|l|}{ Patients with RA } & \multicolumn{3}{|l|}{ Controls } \\
\hline & Any fracture (53) & No fracture (196) & p Value & Any fracture $(50)$ & No fracture (199) & p Value \\
\hline \multicolumn{7}{|l|}{ Demographic variables } \\
\hline Age (years) & $64.5(6.2)$ & $62.6(6.8)$ & 0.06 & $65.1(6.4)$ & $63.0(6.7)$ & 0.04 \\
\hline Height & $163.0(6.7)$ & $164.0(5.8)$ & 0.28 & $165.1(6.1)$ & $163.4(5.7)$ & 0.002 \\
\hline Weight & 67.7 (16.5) & $65.6(11.2)$ & 0.09 & 71.9 (11.2) & 69.0 (12.0) & 0.06 \\
\hline BMI $\left(\mathrm{kg} / \mathrm{m}^{2}\right)$ & $25.4(5.8)$ & $24.2(3.9)$ & 0.08 & $26.4(4.4)$ & $25.8(4.1)$ & 0.13 \\
\hline Age at menopause (years) & $47.6(8.0)$ & $48.8(4.8)$ & 0.16 & $49.8(5.3)$ & $49.4(4.8)$ & 0.38 \\
\hline Current smoker & 35.8 & 32.3 & 0.65 & 22.0 & 31.6 & 0.20 \\
\hline \multicolumn{7}{|l|}{ Clinical variables } \\
\hline Disease duration* & $20.1(10.8)$ & $15.6(10.0)$ & 0.004 & $20.7(11.2)$ & $15.6(10.0)$ & 0.002 \\
\hline Rheumatoid factor positive & 62.0 & 49.2 & 0.12 & & & \\
\hline$M H A Q$ & $1.8(0.6)$ & $1.7(0.5)$ & 0.19 & $1.1(0.2)$ & $1.1(0.3)$ & 0.60 \\
\hline DAS & $4.79(1.33)$ & $4.68(1.22)$ & 0.57 & & & \\
\hline Any deformed joint & 77.4 & 59.2 & 0.02 & & & \\
\hline Fracture before RA diagnosis & 13.2 & 9.2 & 0.38 & 14.0 & 8.6 & 0.30 \\
\hline Long term CS use ( $\geqslant 12$ months) & 64.2 & 50.0 & 0.07 & 0.0 & 3.0 & 0.23 \\
\hline Current oestrogen use & 45.1 & 37.7 & 0.37 & 18.0 & 32.1 & 0.05 \\
\hline Current bisphosphonate use & 21.6 & 9.7 & 0.03 & 0 & 1.5 & 0.40 \\
\hline \multicolumn{7}{|l|}{ BMD variables } \\
\hline BMD femoral neck $\left(\mathrm{g} / \mathrm{cm}^{2}\right)$ & $0.76(0.20)$ & $0.82(0.13)$ & 0.02 & $0.88(0.11)$ & $0.84(0.13)$ & 0.03 \\
\hline BMD total hip $\left(\mathrm{g} / \mathrm{cm}^{2}\right)$ & $0.78(0.19)$ & $0.85(0.14)$ & 0.01 & $0.87(0.13)$ & $0.92(0.13)$ & 0.03 \\
\hline BMD L2-4 $\left(\mathrm{g} / \mathrm{cm}^{2}\right)$ & $1.00(0.24)$ & $1.07(0.19)$ & 0.03 & $1.05(0.19)$ & $1.12(0.19)$ & 0.03 \\
\hline Z score femoral neck & $-0.63(1.00)$ & $-0.17(1.35)$ & 0.01 & $-0.19(0.87)$ & $0.32(0.98)$ & 0.03 \\
\hline Z score total hip & $-0.82(1.24)$ & $-0.31(1.05)$ & 0.01 & $-0.10(0.97)$ & $0.25(0.98)$ & 0.03 \\
\hline Z score of the spine & $-0.11(1.90)$ & $0.36(1.44)$ & 0.05 & $0.16(1.48)$ & $0.68(1.53)$ & 0.03 \\
\hline
\end{tabular}

For abbreviations, see table 1 .

*For controls, disease duration = number of years since dummy time of disease onset, corresponding with the time of disease onset of the matched patient with RA. $p$ value, $t$ tests for continuous and $\chi^{2}$ tests for dichotomous variables.

agree with that previously reported (median 2 years, range $1-15$ years)

\section{Comparison of patients and controls with and without a previous fracture}

Table 2 presents bivariate comparisons of demographic and clinical variables between patients and controls with and without at least one non-vertebral fracture after RA diagnosis. Patients with a positive fracture history had significantly longer disease duration, and were more likely to be current bisphosphonate users and to have at least one deformed joint than patients with a negative fracture history. Older age and a history of long term corticosteroid use were close to being significantly associated with a positive fracture history. BMD, both as raw values and as age and weight adjusted Z scores, was significantly reduced at all measurement sites in patients with a history of at least one fracture after RA diagnosis. In the controls, age, height, "disease duration" (time since dummy year of diagnosis, see section on "Statistical analyses" under "Materials and methods") and lower BMD were significantly associated with a positive fracture history.

\section{Multivariate analysis}

Table 3 shows the results of logistic regression analysis in 249 patients with RA, with a history of any non-vertebral fracture as dependent variable. In the original model, we included age, disease duration, any fracture before RA diagnosis, the presence of any deformed joint, a history of long term corticosteroid use, and BMD. We also controlled for present use of oestrogens or bisphosphonates. An interaction test was performed for age and disease duration, but removed, as it was not significant. Separate analyses were performed for the three sites of BMD measurements. A history of any nonvertebral fracture after RA diagnosis was independently associated with disease duration and with BMD levels, at all three measurement sites. Adjusted for disease duration, the odds ratio for having had any peripheral fracture after RA diagnosis was 1.52 (95\% CI 1.10 to 2.12$)$ for each SD reduction in $\mathrm{Z}$ score of the total hip (table 3 ). The corresponding numbers for $\mathrm{Z}$ score at the femoral neck and lumbar spine (L2-4) were 1.52 ( 1.08 to 2.13) and 1.27 (1.03 to 1.94$)$, respectively. The same models were repeated in the control group, where disease duration corresponded with the time since the dummy year of diagnosis (see section on

Table 3 Possible independent risk factors for non-vertebral fractures in patients with RA and controls. Logistic regression analysis for patients with RA and controls

\begin{tabular}{lrrrr}
\hline & $\boldsymbol{\beta}$ & SE & OR & $95 \% \mathrm{Cl}$ \\
\hline Patients with RA & & & & \\
$\quad$ Disease duration & 0.04 & 0.02 & 1.04 & 1.01 to 1.07 \\
Z score total hip (-1 SD) & 0.42 & 0.12 & 1.52 & 1.10 to 2.12 \\
$\quad$ Constant & -2.32 & 0.42 & & \\
Controls & 0.05 & 0.02 & 1.05 & 1.01 to 1.08 \\
$\quad$ Disease duration* & 0.46 & 0.18 & 1.55 & 1.07 to 2.20 \\
Z score total hip (-1 SD) & -2.16 & 0.34 & & \\
$\quad$ Constant & &
\end{tabular}

*For controls, disease duration = number of years since dummy time of disease onset, corresponding with the time of disease onset of the matched patient with RA. 
"Statistical analyses" under "Materials and methods"). The relationships between $\mathrm{Z}$ score and non-vertebral fractures were similar to those in the patient group (table 3 ).

To explore whether there was any relationship between a history of non-vertebral fracture and a diagnosis of RA, a pooled logistic regression analysis was performed. When controlling for BMD at the total hip, disease duration (number of observed years after dummy time of RA diagnosis in controls), and current use of oestrogens or bisphosphonates, there was no significant relationship between a diagnosis of RA and a history of any non-vertebral fracture (OR $0.77,95 \%$ CI 0.45 to 1.30 ). If the three versus 13 fractures that occurred during skiing or other sports activities were excluded, the odds ratio for any fracture was 1.03 (95\% CI 0.59 to 1.80$)$.

\section{DISCUSSION}

In this cross sectional case-control study we found that a history of non-vertebral fractures in RA was independently associated with lower BMD. We did not find significant associations between past fractures and long term corticosteroid use, or markers of longstanding disease activity, and our study does not support the view that patients with RA are generally more prone to non-vertebral fractures than the background population.

The similarity between the two groups in the number of subjects who reported a previous fracture (53 patients with RA and 50 control subjects, fig 1), and in the time to event analysis (fig 2) was striking. Owing to small numbers, it is not possible to draw any strong conclusions about individual fracture types, except hip fractures. Twice as many humerus fractures occurred in the patients with RA as in the controls, but this difference was not statistically significant. There was, however, no tendency towards a higher incidence of wrist fractures in patients with RA compared with controls $(23 \mathrm{v}$ $28, \mathrm{p}=0.55)$.

To our knowledge, this study is the first to present data on BMD along with information on non-vertebral fractures in patients with RA. Several studies on postmenopausal osteoporosis have established the relationship between fractures and BMD. ${ }^{18}{ }^{19}$ Although conflicting evidence exists, some authors have argued that patients with RA, or patients receiving long term corticosteroid treatment, may fracture on a higher BMD threshold than controls. ${ }^{45-22}$ These conclusions are drawn mainly from studies focusing on vertebral fractures. In our study, both patients and controls with a history of prior fracture had lower age adjusted BMD than those without, and the odds ratios for non-vertebral fracture in logistic regression analysis for each SD Z score unit were similar (tables 1 and 3).

Two previous studies have examined possible risk factors for non-vertebral fractures in RA, suggesting that aging, impaired ambulation and, perhaps, corticosteroid use are independently associated with non-vertebral fractures. ${ }^{11}{ }^{12}$ In 388 female patients with RA, the authors found that the relative risk of non-vertebral fractures was increased by about $50 \%$ compared with the incidence in the general population. By retrospectively examining the patient charts, the authors found that only thinness, aging, and impaired ambulation were independently associated with fracture incidence. In a larger study, Michel et al additionally found an independent relationship between fractures and corticosteroid use, as well as a previous diagnosis of osteoporosis. ${ }^{12}$

We did not find any independent relationship between fracture history and markers of disease severity, disability, or corticosteroid use. Neither could we find any relationship with the number of deformed joints-our best measurement of longstanding disease activity. There are several possible explanations for our findings, and the discrepancy between these and previously published results from other studies. The numbers may be too small and the patients too young to gain statistical power. Most fracture rates increase with age. ${ }^{23}$ Thus, a study focusing on elderly patients might reveal differences between patients and controls not seen in our study. The Oslo Rheumatoid Arthritis Register reflects the entire RA population. Different results might have been reached in a hospital based setting including patients with more severe disease only.

The only previous study comparing overall fracture history between patients and controls was published nearly 20 years ago. ${ }^{11}$ The diagnosis and treatment of RA have changed substantially during the past years, and there are reasons to believe that the total burden of the disease has diminished. ${ }^{24}$ Better awareness and treatment of osteoporosis have been reached during the same period, ${ }^{16}$ as reflected by the relatively large proportion of patients and controls currently taking bone protecting agents (table 1). Bisphosphonates have been shown to reduce the risk of clinical fractures by $30-50 \%$ in women with osteoporosis. ${ }^{25-27}$ A higher proportion of patients with RA than controls were current users of bisphosphonates or oestrogens (table 1). Thus, there is a possibility that the apparently low incidence of fractures in our study is masked partly by the use of bone protecting agents, even if the use of these drugs was controlled for in the multivariate analyses.

The effect of disease activity, disability, and reduced BMD might be opposed by a less physically active lifestyle in patients with RA than in the general population. There was a significant difference in the proportions of subjects who obtained their fractures during skiing or other sports activities. However, excluding these fractures from the analyses did not alter the significance of the overall fracture history between the groups, the differences for individual fracture types, or the results of the pooled multivariate analysis. Still, a more active lifestyle probably partly explains the lack of difference between patients and controls. Patients with an increased risk of osteoporosis should, however, not be discouraged from taking part in physical activity, as this is known to have a protective effect against later fractures by moderately increasing BMD and muscle strength. ${ }^{28}$

There are several limitations to our study. It is cross sectional, so possible risk factors for non-vertebral fractures might have been obtained after the time of the event. Factors such as reduced BMD or impaired ambulation might be consequences of, rather than causes of, any previous fracture. Secondly, all fracture data are self reported. For practical and ethical reasons, it would be impossible to verify the fractures radiographically, or by gaining access to the patient's charts to confirm the time of the fractures. Self reporting has been proved to be fairly reliable in previous publications, especially in postmenopausal women and when considering major fractures and fractures of the upper limbs. ${ }^{29}{ }^{30}$ Our quality control procedure supports the findings from these studies.

Longitudinal studies and studies better powered to examine individual fracture types are needed to draw strong conclusions about non-vertebral fractures in patients with RA. However, our study suggests that BMD is a reliable tool for assessing fracture risk in patients with RA, and to the same extent as that seen in postmenopausal women. It seems that non-vertebral fractures, other than hip and perhaps humerus fractures, are not a substantial medical burden on patients with RA aged less than 72 years. Clinical practice should focus on the prevention of hip and vertebral fractures in this patient group.

\section{ACKNOWLEDGEMENTS}

We gratefully appreciate the expert technical assistance of our research nurses Margareth Sveinsson, Ingerid Müller, Sidsel 
Arnkværn, and Anne Katrine Kongtorp, and the participation in data collection and processing of the medical students Aasne Ask Hyldmo, Siri Seterelv, Pernille Boyesen, and Mathilde Irgens.

\section{Authors' affiliations}

R E Ørstavik, G Haugeberg, T Uhlig, P Mowinckel, T K Kvien, Oslo City Department of Rheumatology, Diakonhjemmet Hospital, Oslo, Norway J A Falch, Department of Internal Medicine, Aker Hospital, Oslo, Norway

J I Halse, Clinic of Osteoporosis, Oslo, Norway

\section{REFERENCES}

1 Haugeberg G, Uhlig T, Falch JA, Halse Jl, Kvien TK. Bone mineral density and frequency of osteoporosis in female patients with rheumatoid arthritis: results from 394 patients in the Oslo County Rheumatoid Arthritis register. Arthritis Rheum 2000;43:522-30.

2 Baltzan MA, Suissa S, Bauer DC, Cummings SR. Hip fractures attributable to corticosteroid use. Study of Osteoporotic Fractures Group. Lancet 1999;353: 1327.

3 de Nijs RN, Jacobs JW, Bijlsma JW, Lems WF, Laan RF, Houben $\mathrm{HH}$, et al Prevalence of vertebral deformities and symptomatic vertebral fractures in corticosteroid treated patients with rheumatoid arthritis. Rheumatology (Oxford) 2001;40:1375-83

4 Naganathan V, Jones G, Nash P, Nicholson G, Eisman J, Sambrook PN. Vertebral fracture risk with long-term corticosteroid therapy: prevalence and relation to age, bone density, and corticosteroid use. Arch Intern Med 2000; 160:2917-22.

5 Peel NF, Moore DJ, Barrington NA, Bax DE, Eastell R. Risk of vertebral fracture and relationship to bone mineral density in steroid treated rheumatoid arthritis. Ann Rheum Dis 1995;54:801-6.

6 Van Staa TP, Leufkens HG, Abenhaim L, Zhang B, Cooper C. Use of oral corticosteroids and risk of fractures. J Bone Miner Res 2000;15:993-1000.

7 Spector TD, Hall GM, McCloskey EV, Kanis JA. Risk of vertebral fracture in women with rheumatoid arthritis. BMJ 1993;306:558

8 Orstavik RE, Haugeberg G, Mowinckel P, Lilleas F, Kvien TK. Vertebral deformities are more prevalent and more strongly related to bone mineral density in rheumatoid arthritis than in matched controls: a case control study [abstract]. Arthritis Rheum 2002;44:S260.

9 Cooper C, Coupland C, Mitchell M. Rheumatoid arthritis, corticosteroid therapy and hip fracture. Ann Rheum Dis 1995:54:49-52.

10 Huusko TM, Korpela M, Karppi P, Avikainen V, Kautiainen H, Sulkava R. Threefold increased risk of hip fractures with rheumatoid arthritis in Central Finland. Ann Rheum Dis 2001;60:521-2.

11 Hooyman JR, Melton U III, Nelson AM, O'Fallon WM, Riggs BL. Fractures after rheumatoid arthritis. A population-based study. Arthritis Rheum 1984;27:1353-61

12 Michel BA, Bloch DA, Wolfe F, Fries JF. Fractures in rheumatoid arthritis: an evaluation of associated risk factors. J Rheumatol 1993;20:1666-9.

13 Arnett FC, Edworthy SM, Bloch DA, McShane DJ, Fries JF, Cooper NS, et al. The American Rheumatism Association 1987 revised criteria for the classification of rheumatoid arthritis. Arthritis Rheum 1988;31:315-24.
14 Kvien TK, Glennas A, Knudsrod OG, Smedstad LM, Mowinckel P, Forre O. The prevalence and severity of rheumatoid arthritis in Oslo. Results from a county register and a population survey. Scand J Rheumatol 1997:26:412-18.

15 Uhlig T, Kvien TK, Jensen JL, Axéll T. Sicca symptoms, saliva and tear production, and disease variables in 636 patients with rheumatoid arthritis. Ann Rheum Dis 1999;58:415-22.

16 Haugeberg G, Orstavik RE, Uhlig T, Falch JA, Halse Jl, Kvien TK. Bone loss in patients with rheumatoid arthritis: results from a population-based cohort of 366 patients followed up for two years. Arthritis Rheum 2002;46:1720-8.

17 van Gestel AM, Haagsma CJ, van Riel PL. Validation of rheumatoid arthritis improvement criteria that include simplified joint counts. Arthritis Rheum 1998:41:1845-50.

18 Marshall D, Johnell O, Wedel H. Meta-analysis of how well measures of bone mineral density predict occurrence of osteoporotic fractures. BMJ 1996;312:1254-9

19 Seeley DG, Browner WS, Nevitt MC, Genant HK, Scott JC, Cummings SR. Which fractures are associated with low appendicular bone mass in elderly women? The Study of Osteoporotic Fractures Research Group. Ann Intern Med 1991;1 15:837-42.

20 Selby PL, Halsey JP, Adams KR, Klimiuk P, Knight SM, Pal B, et al. Corticosteroids do not alter the threshold for vertebral fracture. J Bone Miner Res 2000;15:952-6.

21 Lespessailles E, Poupon S, Adriambelosoa N, Pothuaud L, Siroux V, Bouillon S, et al. Glucocorticoid-induced osteoporosis: is the bone density decrease the only explanation? Joint Bone Spine 2000;67:1 19-26.

22 van Staa TP, Leufkens HG, Cooper C. The epidemiology of corticosteroidinduced osteoporosis: a meta-analysis. Osteoporos Int 2002;13:777-87.

23 Osteoporosis: review of the evidence for prevention, diagnosis and treatment and cost-effectiveness analysis. Introduction. Osteoporos Int 1998;8(suppl 4):S7-80.

24 Kvien TK, Heiberg T, Uhlig T. Improved physical disability scores from 1994 to 2001: results from a population-based rheumatoid arthritis register [abstract]. Ann Rheum Dis 2002;61:S71.

25 Black DM, Cummings SR, Karpf DB, Cauley JA, Thompson DE, Nevitt MC, et al. Randomised trial of effect of alendronate on risk of fracture in women with existing vertebral fractures. Fracture Intervention Trial Research Group. Lancet 1996;348:1535-41.

26 Black DM, Thompson DE, Baver DC, Ensrud K, Musliner T, Hochberg MC, et al. Fracture risk reduction with alendronate in women with osteoporosis: the Fracture Intervention Trial. FIT Research Group. J Clin Endocrinol Metab 2000;85:4118-24.

27 Harris ST, Watts NB, Genant HK, McKeever CD, Hangartner T, Keller M, et al. Effects of risedronate treatment on vertebral and nonvertebral fractures in women with postmenopausal osteoporosis: a randomized controlled trial. Vertebral Efficacy with Risedronate Therapy (VERT) Study Group. JAMA 1999;282:1344-52.

28 Marcus R. Role of exercise in preventing and treating osteoporosis. Rheum Dis Clin North Am 2001;27:131-41.

29 Honkanen K, Honkanen R, Heikkinen L, Kroger H, Saarikoski S. Validity of self-reports of fractures in perimenopausal women. Am J Epidemiol 1999; 150:511-16.

30 Ismail AA O'Neill TW, Cockerill W, Finn JD, Cannata JB, Hoszowski K, et al Validity of self-report of fractures: results from a prospective study in men and women across Europe. EPOS Study Group. Osteoporos Int 2000;1 1:248-54. 